\title{
Theory of Mind in the Early Course of Schizophrenia
}

Nora S Vyas ${ }^{1,2,3^{*}}$, Yi Wang ${ }^{4}$, Shemin S Vyas ${ }^{5}$, Eoin Killackey ${ }^{6}$, Tor-Arne Haugland ${ }^{1}$, and Raymond CK Chan ${ }^{4,7}$

${ }^{1}$ Department of Psychology, Kingston University London, Penrhyn Road, Kingston upon Thames, Surrey, KT1 2EE, UK.

${ }^{2}$ Child Psychiatry Branch, National Institutes of Mental Health, National Institutes of Health, Bethesda, MD, 20892-1600, USA.

${ }^{3}$ Department of Nuclear Medicine, Charing Cross Hospital, Imperial College Healthcare NHS Trust, Fulham Palace Road, London, W6 8RF, UK.

${ }^{4}$ Neuropsychology and Applied Cognitive Neuroscience Laboratory, CAS Key Laboratory of Mental Health, Institute of Psychology, Chinese Academy of Sciences, Beijing, China.

${ }^{5}$ University College London, University College London Hospitals NHS Foundation Trust, 235 Euston Road, Bloomsbury, London, NW1 2BU; Boston Pilgrim Hospital, United Lincolnshire Healthcare NHS Trust, Sibsey Road, Boston, Lincolnshire, PE21 9QS.

${ }^{6}$ Orygen Youth Health Research Centre, 35 Poplar Road, Parkville, Victoria 3052, Australia; Centre for Youth Mental Health, The University of Melbourne, 35 Poplar Road, Parkville, Victoria 3052, Australia.

${ }^{7}$ Department of Psychology, University of Chinese Academy of Sciences, Beijing, China.

* Address correspondence to this author at the Department of Psychology, Kingston University London, Penrhyn Road, Kingston upon Thames, Surrey, KT1 2EE, UK. Tel: +44 (0)208 417 2339; Email: n.vyas@kingston.ac.uk 


\section{ABSTRACT}

Theory of mind deficit is a core feature of schizophrenia and is considered a vulnerability marker of the disorder. The majority of studies measuring theory of mind in schizophrenia involve multiple-episode or chronic schizophrenia patients, and therefore it is important to delineate whether these deficits occur before or following illness-onset by assessing high-risk subjects (clinical high risk and ultra-high risk), early-onset psychosis, and first-degree relatives. We address the question of whether theory of mind impairment is specific or a facet of general cognitive impairment in these clinical populations, and incorporate genetic and neuroimaging studies on theory of mind. The review provides a succinct evaluation of the literature, discusses current limitations and proposes future directions.

Key words: theory of mind, adolescence, neuroimaging, social cognition, unaffected relatives; high risk, endophenotype; mentalising. 


\section{INTRODUCTION}

Schizophrenia is a complex psychiatric disorder with a strong genetic predisposition [1]. Cognitive dysfunction is a well-established feature of schizophrenia, with moderate to severe deficits across a range of domains, including attention, verbal learning and memory, working memory and executive functions [2, 3, 4]. Neurocognitive deficits have consistently been shown to be associated with functional outcome, such as social functioning, social skills, and independent living skills in schizophrenia $[5,6]$. Social cognition has been argued to have a strong relationship with work-related social skills and occupational outcome than neurocognition outcome [7].

A key element of social cognition is Theory of Mind (ToM), which refers to the ability of an individual to represent and make attributes about the mental state of another [8]. It has been shown that this capacity is in deficit in psychotic illnesses from the ultrahigh risk and first episode stages [9] through to established illness such as schizophrenia [8, 10]. Theory of mind deficits has been shown to be highly associated with community functioning in people with psychosis [9].

A number of different tasks have been developed over the years in order to assess ToM [10]. False belief tasks require the participant to understand that other people with different information about a situation may have other beliefs about the situation. A second order false belief task assesses whether the individual is able to understand that a character in the story has a belief about the beliefs of another character. An intentioninferencing task requires an individual to infer the intention of a character from information provided in a short story. Other tasks examine the capacity of individuals to derive meaning from indirect speech such as irony and metaphors [10].

Theory of mind is a capacity that develops normally through childhood. Children develop the capacity to understand first order false belief (i.e. that other people have different views about a situation from themselves) about the age of 4 years, and second order false belief (that people can have mental representations of the mental states of others) by 6 years of age [11]. As noted, deficits of ToM become apparent before the onset of psychotic disorder [9] and are also present in a variety of other neurodevelopmental disorders including bipolar disorders [12], autism spectrum disorders [13, 14], attention-deficit/hyperactivity disorder [15, 16] and specific language impairment $[17,18]$. 
Over the last two decades there has been an upsurge of research interest in understanding ToM in schizophrenia. In this brief, not exhaustive review, we provide an evaluation of the literature on ToM deficits in children and adolescents with schizophrenia, clinical high risk (CHR) and ultra-high risk (UHR) populations, and firstdegree relatives. We discuss the association of ToM with other cognitive processes, and broadly identify the genetic basis of ToM deficits in schizophrenia. A selection of key neuroimaging studies using MRI and functional neuroimaging techniques are described and evaluated. Finally, we provide conclusions and suggestions for future work.

\section{THEORY OF Mind STUdies}

\subsection{Children and adolescents with schizophrenia}

Early onset schizophrenia (EOS) presents in childhood or adolescence typically before the age of 18 , is a relatively rare, clinically severe and chronic form of the illness [19, 20]. EOS is associated with greater disease severity [21-24], developmental delays [2528], higher rates of chromosomal abnormalities and greater burden of copy number variants [29-33], and poor prognosis [34-36] compared with the adult onset counterpart. Furthermore, patients with EOS demonstrate significant cognitive impairments in specific domains, mainly general intellectual ability [36-42], memory [43-47], attention [43, 48, 49], and executive function [46, 48, 50, 51]. Studying early-onset cases may provide important insights into the etiopathogenesis of the disorder [50-51]. However, there has been limited research addressing impairments in social cognition in young people with schizophrenia.

Over the past several decades, ToM deficits were considered unique to autism spectrum disorder [52], however subsequent research revealed that ToM deficits also appear to develop in schizophrenia [53, 54]. Frith [53] suggested that schizophrenia may represent a disorder of mental state representations, based on evidence that ToM deficits are related to positive symptoms. Langdon and coworkers stated that the positive symptoms are a form of hyper-mentalizing, and ToM in schizophrenia appears to be unsynchronized either as an impairment or inflexibility of understanding social interactions and over-attribution of mental states and the intentions of others [55]. Pilowsky et al. [56] compared ToM abilities in COS patients, children with high- 
functioning autism and typically developing (TD) children using a ToM test battery, specifically the fact and value belief task, deception task, and false belief task. The results showed that compared with TD children, COS patients showed no difference on the fact and value tasks, and performance was significantly better on the deception task. However, patients with COS performed significantly worse on the false belief task compared with TD children. Additionally the study revealed that both clinical groups showed ToM deficits in measures underpinning first- and second-order task demands. Some authors have argued that patients with COS may have intact ToM abilities until their first psychotic episode [53].

\subsection{First-episode psychosis}

Several studies have consistently reported that first-episode psychosis present with social cognitive impairments, suggesting that these impairments may be an underlying trait at the time of illness onset $[57,58]$. A few studies that have examined social cognition in first-episode psychosis report deficits in facial affect recognition compared with non-psychiatric controls [58-61]. Inoue and colleagues [62] investigated ToM ability in first-episode schizophrenia in remission and matched controls, using a cartoon picture story which comprised of a first-order and second-order false belief, a reality question and a tactical deception. There was a significant difference between groups on sequencing of the cartoon story. Additionally, patients in remission underperformed on the second order false belief task compared with controls, and the sum score of all outcome variables showed that the first-episode group performed significantly less well than controls. Another study used the Reading the Mind in the Eyes Test Revised to measure ToM in first-episode schizophrenia compared with outpatients with nonpsychotic major depressive disorder, individuals in the general community, and students from an undergraduate university course [63]. Patients with schizophrenia showed a poor total accuracy compared with community controls and university controls but no difference compared with the depression group. The findings support the notion that first-episode patients show specific first-order ToM impairments, which has been reported in previous studies [64, 65].

Several lines of evidence demonstrate ToM deficits in patients with first-episode psychosis $[62,66]$. Studying this population is particularly fruitful in understanding the precise illness process when ToM impairments occurs since there are fewer effects of 
long-term medication use and prolonged duration of psychosis. Achim and colleagues [67] investigated ToM using a combination of mentalizing stories (hinting task, false belief task, fauz-pas test and the strange stories test) in 31 first-episode psychosis patients and 31 matched controls. Compared with other tasks which measured social cue recognition and social knowledge, the greatest impairments in first-episode psychosis patients were reported in mentalizing tasks. Similar findings have been reported in a study utilising the Hinting task and the interpretation of visual jokes task to measure ToM in first-episode psychosis, which showed the largest effect size for the ToM tasks [68].

A recent study used a variety of measures of social cognition, namely the BellLysake Emotional Recognition Task, Hinting Task [53], and the Reading the Mind in the Eyes Test, in a group of first episode psychosis $(n=26)$, participants with prolonged psychosis $(n=72)$, and a psychiatric normal controls group $(n=14)$ [69]. The results showed no difference on any measures between first-episode and prolonged psychosis cohort, however first-episode patients performed significantly less well than psychiatric controls on the eyes test (total score) and hinting task. Langdon and co-workers [70] studied mentalising in first-episode patients $(n=23)$ and matched controls $(n=19)$ using three measures: non-verbal picture-sequencing task, joke appreciation task, and story comprehension task. The authors reported large deficits in ToM (among other neurocognitive measures such as verbal memory and semantic fluency) in first-episode patients compared with healthy controls. These findings harmonize with evidence that ToM impairments occur in the early stages of illness [71]. Adopting a family-based casecontrol design, Ho and colleagues [72] measured first-episode schizophrenia and healthy controls using the (a) Chinese version of the computerized Yoni Task, which consists of first- and second-order mental state inferences (cognitive ToM, affective ToM, and physical inference); (b) Faux Pas task developed from the Faux Pas Recognition test. Contrary to previous studies [73, 74], this study showed no group differences in the first-order ToM tasks, however patients performed less well on cognitive and affective components of the second-order mentalisation task compared with controls. Additionally, first-episode patients performed significantly less well on the faux pas recognition and understanding questions (no difference on control questions) in comparison with healthy controls [72].

First-episode schizophrenia patients show first-order ToM deficits, however there are some discrepancies in the findings. The evidence suggests ToM deficits might be a 
trait marker for schizophrenia. An important question is whether ToM impairments are attributed to deficits in other neurocognitive functions, such as verbal learning and memory, attention, and executive function.

\subsection{Clinical High Risk and Ultra-High Risk for Psychosis}

There has been an upsurge of research interest in studying "ultra-high risk" (UHR) and "clinical high risk" (CHR) populations. Cognitive deficits are reported in individuals who are at CHR for psychosis [75-77], however there are relatively few studies on social cognitive deficits or the relative degree of impairments between first-episode and UHR and CHR populations [78]. Stanford and colleagues [79] measured ToM using the first and second-order false belief cartoon tasks and two higher-order task ('Strange Stories Task' and the 'Reading the Mind in the Eyes' task) in a group of 63 CHR and 24 healthy youths, and 13 schizophrenia patients and 14 adult controls. They reported significant errors in the first- and second-order ToM task in schizophrenic patients compared with controls. There was no difference in ToM performance between CHR patients and the matched youth comparison group. Further, the authors found that performance on the high-order ToM tasks was 'undeveloped' in the high risk group and normal youths, suggesting that higher-order cognitive processes and executive function develops after a full transition from adolescence to adulthood. Another study used three different measures of social cognition (emotion processing was measured using the MayerSalovey-Caruso Emotional Test, ToM was assessed using the Awareness of Social Inference Test, and social relationships measured using the Relationships Across Domains Test) in three independent groups, namely (a) 50 UHR for psychosis and 34 matched controls, (b) 81 first-episode schizophrenia patients, and 46 matched controls; (c) 53 chronic schizophrenia patients versus 47 matched normal volunteers [5]. The results showed poor performance across all social cognitive measures in all clinical groups, however group differences were found to be similar regardless of phase of illness [5]. On the contrary, Thompson and coworkers [68] used three specialized measures of social cognition, including ToM (hinting task and interpretation of visual jokes), facial and vocal recognition (Diagnostic Assessment of Nonverbal accuracy) and social perception (Mayer-Salovey-Caruso Emotional Intelligence Test) in a group of UHR subjects, first-episode psychosis patients and normal controls, where the authors found that UHR patients performed at an intermediate level on all social cognition tasks, 
with first-episode psychosis patients performing worse compared with controls. Further research is required on ToM performance in $\mathrm{CHR}$ and UHR subjects to delineate whether ToM is a risk (predictor) factor for those who make a transition to psychosis.

\subsection{First-degree relatives of schizophrenia}

Over the last decade there is been an upsurge of research interest in studying nonpsychotic relatives of patients to evaluate whether they have a genetic predisposition to impairments in ToM, which are comparable to reported evidence of cognitive impairments in first-degree relatives of schizophrenia [76, 80, 81].

Versmissen and colleagues investigated mentalising, using the Hinting Task, in varying levels of psychosis vulnerability groups, namely 40 patients with psychosis, 49 nonpsychotic biological relatives (familial risk), 41 controls with high levels of psychotic experiences and 54 healthy controls, to assess the degree of ToM impairments [82]. The authors found that relatives performed at an attenuated level compared with controls, while there was a strong association between task performance and clinical patient group. A study by Anselmetti et al. [83] assessed relatives of schizophrenia patients and healthy controls using the ToM picture sequencing task, and reported ToM deficits in parents (separate score for mother and father) of patients with schizophrenia. Similarly, other studies have found genetic liability effects in first-degree relatives [84-88]. Montag and colleagues reported impairments in ToM reasoning in parents and siblings of schizophrenic patients (not explained by other aspects of neurocognitive measures) using the 'Movie for the Assessment of Social Cognition' video-based task [87]. de Achával and colleagues [89] found that unaffected first-degree relatives showed underperformance on the Faces Test, Reading the Mind in the Eyes Test and the detection of social Faux Pas. Similar to previous studies, as above, ToM impairments were reported independent of performance in general cognitive processes.

Although there are numerous studies reporting ToM impairments in first-degree relatives, some studies have shown no differences in ToM reasoning between nonpsychotic first-degree relatives and controls. Some studies measuring the ability to identify mental states of a person through the images (depicted in a photograph) of eyes [90] and the Hinting task (comprehension Hinting statements) [91] showed no impairments in ToM in non-psychotic relatives of patients with schizophrenia compared with controls. Pentaraki and colleagues [92] measured ToM using the first-order and 
second-order ToM stories, and the Revised Eyes Test in patients with schizophrenia, their unaffected parents (separate score for father and mother), compared with matched healthy controls according to group. They reported significant deficits in first-order ToM tasks (but not second-order ToM), however these were related to deficits in general intellectual ability.

The evidence suggests that unaffected relatives perform significantly less well than controls on ToM performance, and these differences appear to be intermediate to individuals with schizophrenia. Furthermore, the magnitude of deficits appear to be similar to numerous cognitive studies reported in relatives $[80,81]$

\section{ASSOCIATION OF THEORY OF MIND WITH OTHER COGNITIVE DOMAINS}

First-episode psychosis patients demonstrate deficits in ToM tasks compared with healthy controls [62, 63 66]; however it is unclear whether ToM impairments interact with or is explained by general cognitive deficits found in schizophrenia. A quantitative review of 204 studies yielding 22 mean effect sizes was carried out by Heinrichs and Zakzanis [93] to measure global cognitive function and selective measure of specific cognitive domains. They reported moderate to large effect size for all neurocognitive measures, where mentalizing impairments were ranked fourth. Several studies reviewed above covaried for age, symptoms, general intellectual ability and other cognitive variables, and point out that patients with schizophrenia show specific ToM impairments. Koelkebeck and colleagues [94] investigated ToM ability in relation to other cognitive functions and clinical measures in 23 first-episode schizophrenia patients and matched healthy controls, and underlined previous studies suggesting a moderate influence of general cognitive deficits and limited influence of clinical symptoms, empathy or conditions of alexithymia on ToM performance. In a recent study on first-episode schizophrenia $(\mathrm{n}=36)$ and a matched control group, Bliksted et al. [95] showed that social cognition contributed to $24 \%$ of the variance, and theory of mind performance were the other multivariate variability, while cognition and symptom scores contributed to a small proportion of the patient group, suggesting that impairments in social cognition may have two subtypes: one type may be associated with general intellectual ability, while the second version may contribute to less complex forms of social cognition not influenced by IQ. The studies shed light on the complex nature of social cognition in 
schizophrenia, and its relation with intelligence. There is a need to investigate both versions of this distinct pattern in a larger more-focused study.

\section{GENETIC CONTRIBUTION OF THEORY OF MIND DEFICITS}

There is a relative paucity of studies of the genetic contribution to ToM deficits in schizophrenia. Several studies have investigated the influence of single nucleotide polymorphisms (SNP) for the development ToM deficits in schizophrenia. Evidence suggests a role of the serotoninergic and dopaminergic system in mentalizing ability. Abnormalities in the serotoninergic system in schizophrenia lead to cognitive deficits in schizophrenia which influence ToM performance, argued to be mediated by executive function abilities [96-99].

The serotonin receptor $1 \mathrm{~A}(5 H T 1 A-R)$ has been associated with several cognitive domains, including executive control, information processing, and episodic memory $[100,101]$, and activation of the $5 \mathrm{HT} 1 \mathrm{~A}$ receptors increases dopamine release in the prefrontal cortex $[102,103]$. In a sample of 118 patients with schizophrenia, Bosia and colleagues [103] investigated the effect of $5 H T 1 A-R-1019 \mathrm{C} / \mathrm{G}$ functional polymorphism on ToM performance, as measured using the ToM picture sequencing task, and reported that CC genotype carriers performed significantly better on the picture sequencing task compared with $\mathrm{CG}$ and $\mathrm{GG}$ genotypes. The study confirmed the influence of $5 \mathrm{HT} 1 \mathrm{~A}-\mathrm{R}$ on cognitive function and its role in the ability to mentalize [103]. Several lines of evidence support a dysregulation of subcortical dopamine system as an etiology of schizophrenia [104-106]. The role of dopamine transmission in impairments in the ToM in schizophrenia has been explored between genes encoding dopamine receptor D2 (DRD2) and the enzyme of catecholamine metabolism, catechol-Omethyltransferase (COMT). Alfimova et al. [107] investigated the association between ToM, as measured using the second-order false beliefs task, and DRD2 receptor and COMT Val158Met polymorphism in 209 individuals with schizophrenia and 172 healthy controls. The authors reported a significant gender effect and an association between the COMT gene and effective performance in solving the false beliefs tasks in schizophrenia. Females who were Met158 allele carriers underperformed on the task compared with $\mathrm{Val} / \mathrm{Val}$ genotype, while males with the $\mathrm{Val} / \mathrm{Val}$ genotype showed marked 
impairments on the task compared with the Met158 allele group [107]. The evidence suggests that the coupling between the serotonergic and dopaminergic system is critical for the development of ToM.

Several studies have reported that the SNP rs1344706 of the zinc-finger protein gene (ZNF804A) is strongly implicated in schizophrenia [108-110]. Hargreaves et al. [111] studied the association between performance on two mental state reasoning tasks (Eyes of the Mind and Hinting tasks) and a common variant within ZNF804A in patients with schizophrenia and healthy controls. Contrary to a previous study from the same group in healthy volunteers [112], the authors did not find an association between the risk allele in either group, however healthy controls (not schizophrenia patients) with the A risk allele at rs1344706 showed greater personalizing bias scores compared with non-carriers [111]. The study underlines the differences in gene by cognitive (ToM) phenotype results between schizophrenia patients and controls, and emphasizes the need to exercise caution in applying findings based on healthy participants to exploring the neural mechanisms in clinical patients, particularly concerning the influence of ZNF804A.

Evidence suggests that individual genes have been associated with ToM in schizophrenia. However, the precise influence of gene expression on mentalizing ability in this heterogeneous and complex disorder has not been fully explored. Further research is warranted to confirm ToM as a cognitive endophenotype for schizophrenia.

\section{NEUROIMAGING STUDIES OF THEORY OF MIND DEFICITS IN SCHIZOPHRENIA}

Neuroimaging studies in healthy population has suggested a ToM brain network, of which the medial prefrontal region (MPFC) and the temporo-parietal junction (TPJ) have been found to be the most robust regions involved in mentalizing processing [113-115]. Different paradigms have been adopted in previous fMRI studies to examine the neural correlates of ToM and different types of the stimuli have been used, such as cartoon stories, video of the biological animation, and mind in the eyes. The common feature of such tasks is asking participants to "referring others' mental state". For example, in a cartoon metalizing task, a series of comic strips were presented and participants were asked to choose an appropriate ending for the story 
with referring the intentions of the characters [116, 117]. Most recently, a metaanalysis reviewed imaging studies adopted different ToM tasks and evidenced a core network including mPFC and posterior TPJ which is commonly activated during the mentalising across different tasks or stimuli types [118].

Both brain structural and functional abnormalities associated with the ToM deficits have been reported in patients with schizophrenia. For example, impaired ToM performance in schizophrenia patients were found to be associated with the reduction of grey matter volume in the ventral medial prefrontal cortex [119] and the superior temporal sulcus (STS) [120-121]. In addition, adopting the functional imaging tasks, previous studies also found the reduced brain activities in the mPFC and the TPJ in patients with schizophrenia [122]. An imaging study adopted a false belief task in patients with schizophrenia or schizoaffective disorders and healthy controls, and requests participants to read the stories on the screen, understand the false content and then metallize the mental states to the characters in the story. The results showed that, compared to controls, patients with schizophrenia had reduced activity in mPFC during the ToM task; in addition, further analysis also showed that the reduced activity in $\mathrm{mPFC}$ is related to the social anhedonia and social functioning [123]. Lee et al. [124] conducted an fMRI study in patients with schizophrenia during an acute episode and after recovery. The results showed that the brain activity in mPFC of schizophrenia patients increased after recovery compared to their acute episode [124]. On the contrary, previous studies have found increased brain activation in individuals at-risk (prodromal) of developing schizophrenia [125] as well as individuals with psychosis proneness [126]. The former study was conducted in prodromal individuals for psychosis ( $n=10$, mean age $=25.5$ years) using the mental states attribution task presented using cartoons [125]. The results showed that prodromal individuals showed greater activation in the ToM neural network [including prefrontal cortex, the posterior cingulate and temporo-parietal cortex] than healthy controls. Modinos and colleagues [126] examined the neural correlates of ToM in individuals with high psychosis proneness $(n=18$, mean age 19.8, range from 18 to 24 years) measured by the positive subscale of the Community Assessment of Psychic Experiences questionnaire (CAPE). They adopted the Yoni task developed by Shamay-Tsoory et al. [127] which presents a face in the middle and four figures of objects in the corners of the screen and consists of first- and second- order attributions of the cognitive and affective mental states. The results showed that 
individuals with high psychosis proneness had stronger activations in dorsomedial and lateral prefrontal regions than the matched controls during the second order mentalizing. Most recently, researchers have also reported positive correlations between negative schizotypy measured by the Chapman Social Anhedonia Scale [128] and brain activation changes during a cartoon mentalising task in the mPFC and the TPJ in a college sample [129]. These findings suggest an important role of the mPFC during the mentalising for the development of the schizophrenia which might be a compensation mechanism in high risk population and also an indicator for the schizophrenia patients.

Although behavioural studies have shown that first-degree relatives of patients with schizophrenia also have deficits on ToM, imaging studies in this sample are quite scarce. Marjoram et al. [88] conducted the first neuroimaging study in relatives of schizophrenia patients and they used a visual joke paradigm with one condition requires mentalizing ability to understand jokes or another condition does not. The results showed that relatives who were symptomatic showed less activation in bilateral prefrontal regions than symptomatic relatives as well as controls [88]. Adopting a false belief imaging task, the reduced brain activation in the TPJ was also observed in 19 individuals with familial high risk (with at least two affected relatives) [130].

Differentiating self and others is another important component during the mentalising. Recently, an fMRI study examined the neural correlates of the selfinhibition in ToM in eighteen individuals with high psychosis proneness measured by the positive subscale of CAPE [131]. The task consists of the movie clips presenting the false belief situation between two real persons and manipulated to be high and low inhibition conditions or control condition. The results showed that individuals with high psychosis proneness showed greater activation in inferior frontal gyrus during the self-perspective inhibition but not during the stop signal task than individuals with low psychosis proneness. The researchers suggest that individuals with high psychosis proneness need more resources for inhibiting the self-perspective when they mentalized to others [131].

The fMRI studies of ToM in early stage of the schizophrenia spectrum, such as individuals with psychosis proneness, prodromal and first episode patients, and the unaffected relatives are still limited. There is a pressing need for more research to assess the degree of social impairment and their neural correlates in various clinical 
groups to understand the neurodevelopmental features related to the ToM deficits of schizophrenia. Particularly, the reverse activation pattern of the MPFC in established schizophrenia patients and high-risk populations calls for further investigation. In addition, the associations between dimensions of symptoms, executive functions and neural correlates of the ToM need to be extensively examined in future studies.

\section{CONCLUSIONS}

Theory of mind impairments in first episode schizophrenia appear to be similar to chronic schizophrenia [132, 133], and the studies suggest that these patients show specific deficits in ToM in the early stages of illness and are not influenced by symptom severity, course of illness, long-term exposure to medication, or other potential predictors of ToM. Unaffected relatives of schizophrenia patients, including parents, display deficits in ToM and other social cognitive measures, performing at an intermediate level to patients and normal controls. The findings suggest that the familial traits are rather specific, and are not explained by additional factors such as age, years of education, IQ, and general cognitive abilities. Future work should focus on longitudinal investigation of ToM impairments in first-degree relatives. Additionally it is important to discover the neuropsychometric properties of the various ToM measures used in this field. Further research is likely to improve early detection and prediction of schizophrenia, by understanding the developmental trajectories of the mentalising process in those who make a transition to psychosis.

\section{ACKNOWLEDGMENTS}

Dr Nora S Vyas was supported by the Fulbright Distinguished Scholar Award by the US-UK Fulbright Commission, and more recently by the Lindemann Trust Fellowship by the English-Speaking Union. Dr Yi Wang was supported by a National Science Fund China (31400884). Professor Raymond Chan was supported by a National Science Fund China (81088001, 91132701), and a grant from Beijing Training Project for the Leading Talents in S \& T (Z151100000315020).

\section{REFERENCES}


[1] Sullivan PF, Kendler KS, Neale MC. Schizophrenia as a complex trait: evidence from a meta-analysis of twin studies. Arch Gen Psychiatry 2003; 60: 1187-92.

[2] Heinrichs RW, Zakzanis KK. Neurocognitive deficits in schizophrenia: a quantitative review of the literature. Neuropsychology 1998; 12: 426-45.

[3] Fioravanti M, Carlone O, Vitale B, Cinti ME, Clare L. A meta-analysis of cognitive deficits in adults with a diagnosis of schizophrenia. Neuropsychol Rev 2005; 15: 73-95.

[4] Schaefer J, Giangrande E, Weinberger DR, Dickinson D. The global cognitive impairment inschizophrenia: consistent over decades and around the world. Schizophr Res 2013; 150: 42-50.

[5] Green MF, Bearden CE, Cannon TD, Fiske AP, Hellemann GS, Horan WP, Kee K, Kern RS, Lee J, Sergi MJ, Subotnik KL, Sugar CA, Ventura J, Yee $\mathrm{CM}$, Nuechterlein $\mathrm{KH}$. Social cognition in schizophrenia, Part 1: performance across phase of illness. Schizophr Bull 2012; 38: 854-64.

[6] Green MF, Horan WP, Lee J. Social cognition in schizophrenia. Nat Neurosci Rev 2015; 16: 620-31.

[7] Bell M, Tsang HWH, Greig TC, Bryson GJ. Neurocognition, social cognition, perceived social discomfort, and vocational outcomes in schizophrenia. Schizophr Bull 2009; 35: 738-47.

[8] Frith CD, Corcoran R. Exploring 'theory of mind' in people with schizophrenia. Psychol Med 1996; 26: 521-30.

[9] Bartholomeusz CF, Allott K. Neurocognitive and social cognitive approaches for improving functional outcome in early psychosis: theoretical considerations and current state of evidence. Schizophr Res Treatment 2012; 815315. doi: $10.1155 / 2012 / 815315$

[10] Sprong M, Schothorst P, Vos E, Hox J, van Engeland H. Theory of mind in schizophrenia: meta-analysis. Br J Psychiatry 2007; 191: 5-13.

[11] Hollebrandse B, van Hout A, Hendriks P. Children's first and second-order false-belief reasoning in a verbal and a low-verbal task. Synthese 2014; 191: 321-333.

[12] Bora E, Vahip S, Gonul AS, Akdeniz F, Alkan M, Ogut M, Eryavuz A. Evidence for theory of mind deficits in euthymic patients with bipolar disorder. Acta Psychiatr Scand 2005; 112: 110-116

[13] Baron-Cohen S 1995 Mindblindness: An Essay on Autism and Theory of Mind. The MIT Press/Bradford, Cambridge pp 1-7.

[14] Varga S. Pretence, social cognition and self-knowledge in autism. Psychopathology 2010; 44: 46-52.

[15] Uekermann J, Kraemer M, Abdel-Hamid M, Schimmelmann BG, Hebebrand J, Daum I, Wiltfang J, Kis B. Social cognition in attention-deficit hyperactivity disorder (ADHD). Neurosci Biobehav Rev 2010; 34: 734-43.

[16] Mary A, Slama H,Mousty P, Massat I, Capiau T, Drabs V, Peigneux P. Executive and attentional contributions to theory of mind deficit in attention deficit/hyperactivity disorder (ADHD). Child Neuropsychol 2015; 12: 1-21.

[17] Gillott A, Furniss F, Walter A. Theory of mind ability in children with specific language impairment. Child Lang Teach Ther 2004; 20: 1-11.

[18] Farrant BM, Fletcher J, Maybery MT. Specific Language Impairment, Theory of Mind, and Visual Perspective Taking: Evidence for Simulation Theory and 
the Developmental Role of Language. Child development 2006; 77: 1842-53.

[19] Rapoport JL, Gogtay N. Childhood onset schizophrenia: support for a progressive neurodevelopmental disorder. Int J Dev Neurosci 2011; 29: $251-58$.

[20] Vyas NS, Gogtay N. Treatment of early onset schizophrenia: recent trends, challenges and future considerations. Front Psychiatry 2012; 3: 29. doi: 10.3389/fpsyt.2012.00029.

[21] Werry JS, McClellan JM, Chard P. Childhood and adolescent schizophrenia, bipolar and schizoaffective disorders: a clinical and outcome study. J Am Acad Child Adolesc Psychiatry 1991; 30: 457-465.

[22] Eggers C, Bunk D. The long-term course of childhood-onset schizophrenia: a 42- year followup. Schizophr Bull 1997; 23: 105-17.

[23] Watkins JM, Asarnow RF, Tanguay PE. Symptom development in childhood onset schizophrenia. J Child Psychol Psychiatry 1988; 29: 865-878 .

[24] Cannon M, Caspi A, Moffitt TE, Harrington H, Taylor A, Murray RM, Poulton R. Evidence for early-childhood, pan- developmental impairment specific to schizophreniform disorder: results from a longitudinal birth cohort. Arch Gen Psychiatry 2002; 59: 449-456.

[25] Driver DI, Gogtay N, Rapoport JL. Childhood onset schizophrenia and early onset schizophrenia spectrum disorders. Child Adolesc Psychiatr Clin N Am 2013; 22: 539-55.

[26] Nicolson R, Lenane M, Singaracharly S, Malaspina D, Giedd JN, Hamburger SD, Gochman P, Bedwell J, Thaker GK, Fernandez T, Wudarsky M, Hommer DW, Rapoport JL. Premorbid speech and language impairments in childhoodonset schizophrenia: association with risk factors. Am J Psychiatry 2000; 157: 794-800.

[27] Addington AM, Rapoport JL. The genetics of childhood-onset schizophrenia: when madness strikes the prepubescent. Curr Psychiatry Rep 2009; 11: 15661.

[28] Vyas NS, Ahn K, Stahl` DR, Caviston P, Simic M, Netherwood S, Puri BK, Lee Y, Aitchison KJ. Association of KIBRA rs17070145 polymorphism with episodic memory in the early stages of a human neurodevelopmental disorder. Psychiatry Res 2014; 220: 37-43.

[29] Rapoport JL, Giedd JN, Gogtay N. Neurodevelopmental model of schizophrenia: update 2012. Mol Psychiatry 2012; 17:1228-38.

[30] Vyas NS, Puri BK. Evidence of an association between brain-derived neurotrophic factor Val66Met gene polymorphism and general intellectual ability in early-onset schizophrenia. Isr J Psychiatry Relat Sci 2012; 49: 137-42.

[31] Ahn K, Gotay N, Andersen TM, Anvari AA, Gochman P, Lee Y, Sanders S, Guha S, Darvasi A, Glessner JT, Hakonarson H, Lencz T, State MW, Shugart YY,Rapoport JL. High rate of disease-related copy number variations in childhood onset schizophrenia. Mol Psychiatry 2014; 19:568-72.

[32] Vyas NS, Hadjulis M, Vourdas A, Byrne P, Frangou S. The Maudsley early onset schizophrenia study. Predictors of psychosocial outcome at 4-year follow-up. Eur Child Adolesc Psychiatry 2007; 16:465-70.

[33] Lay B, Blanz B, Hartmann M, Schmidt MH. The psychosocial_outcome_of adolescent-onset schizophrenia: a 12-year followup. Schizophr Bull 2000; 26: 801-16.

[34] Díaz-Caneja CM, Pina-Camacho L, Rodríguez-Quiroga A, Fraguas D, 
Parellada $\quad \mathrm{M}$, Arango C. Predictors of outcome $n$ early-onset psychosis: a systematic review. NPJ schizophrenia 2015; 1: 14005 doi:10.1038/npjschz.2014.5

[35] Kumra S, Wiggs E, Bedwell J, Smith AK, Arling E, Albus K, Hamburger SD, McKenna K, Jacobsen LK, Rapoport JL, Asarnow RF. Neuropsychological deficits in pediatric patients with childhood-onset schizophrenia and psychotic disorder not otherwise specified. Schizophr. Res 2000; 42: 135144.

[36] Bedwell JS, Keller B, Smith AK, Hamburger S, Kumra S, Rapoport JL. Why does postpsychotic IQ decline in childhood-onset schizophrenia? Am J Psychiatry 1999; 156: 1996-97.

[37] Gochman PA, Greenstein D, Sporn A, Gogtay N, Keller B, Shaw P, Rapoport JL. IQ stabilization in childhood-onset schizophrenia. Schizophr Res 2005; 77: 271-277.

[38] Fagerlund B, Pagsberg AK, Hemmingsen RP. Cognitive deficits and levels of IQ in adolescent onset schizophrenia and other psychotic disorders. Schizophr Res 2006; 8: 30-39.

[39] McClellan J, Prezbindowski A, Breiger D, McCurry C. Neuropsychological functioning in early onset psychotic disorders. Schizophr Res 2004; 68: 21-6.

[40] White T, Ho BC, Ward J, O'Leary D, Andreasen NC. Neuropsychological performance in first-episode adolescents with schizophrenia: a comparison with first-episode adults and adolescent control subjects. Biol Psychiatry 2006; 60: $\quad 463-71$.

[41] Brickman AM, Buchsbaum MS, Bloom R, Bokhoven P, Paul-Odouard R, Haznedar MM, Dahlman KL, Hazlett EA, Aronowitz J, Heath D, Shihabuddin L. Neuropsychological functioning in first-break, nevermedicated adolescents with psychosis. J Nerv Ment Dis 2004; 192: 615-22.

[42] Roofeh D, Cottone J, Burdick KE, Lencz T, Gyato K, Cervellione KL, Napolitano B, Kester H, Anderson B, Kumra S. Deficits in memory strategy use are related to verbal memory impairments in adolescents with schizophrenia-spectrum disorders. Schizophr Res 2006; 85: 201-12.

[43] Landró N, Ueland T. Verbal memory and verbal fluency in adolescents with schizophrenia spectrm disorders. Psychiatry Clin Neurosci 2008; 62: 653-61.

[44] Kenny JT, Friedman L, Findling RL, Swales TP, Strauss ME, Jesberger JA, Schulz SC. Cognitive impairment in adolescents with schizophrenia. Am J Psychiatry 1997; 154: 1613-15.

[45] Vyas NS, Patel NH, Puri BK. Neurobiology and phenotypic expression in early onset schizophrenia. Early Interv Psychiatry 2011; 5: 3-14.

[46] Kumra S, Wiggs E, Bedwell J, Smith AK, Arling E, Albus K, Hamburger SD, McKenna K, Jacobsen LK, Rapoport JL, Asarnow RF. Neuropsychological deficits in pediatric patients with childhood-onset schizophrenia and psychotic disorder not otherwise specified. Schizophr Res 2000; 42: 135-44.

[47] Vyas NS, Kumra S, Puri BK. What insights can we gain from studying earlyonset schizophrenia? The neurodevelopmental pathway and beyond. Expert Rev Neurother 2010; 10: 12437.

[48] Øie M, Rund BR. Neuropsychological deficits in adolescent-onset schizophrenia compared with attention deficit hyperactivity disorder. Am J Psychiatry 1999; 156: 216-22.

[49] Fagerlund B, Pagsberg AK, Hemmingsen RP. Cognitive deficits and levels of $\mathrm{IQ}$ in adolescent onset schizophrenia and other psychotic 
disorders. Schizophr Res 2006; 8: 30-39.

[50] Jacobsen L, Rapoport, J. Childhood-onset schizophrenia: implications of clinical and neurobiological research. J Child Psychol Psychiatry 1998; 38: 607-712.

[51] Gogtay N, Vyas NS, Testa R, Wood SJ, Pantelis C. Age of onset of schizophrenia: perspectives from structural neuroimaging studies. Schizophr Bull 2011; 37: 504-13.

[52] Baron-Cohen, S. Are autistic children behaviorists? An examination of their mental-physical and appearance-reality distinctions. J Autism Dev Disord 1989; 19: 579-600.

[53] Frith, C. [1992] Schizophrenia as a disorder of self-awareness. The cognitive Neuropsychology of schizophrenia. Erlbaum Hove, pp. 113-135.

[54] Corcoran R, Mercer G, Frith CD. Schizophrenia, symptomatology and social inference: investigating "theory of mind" in people with schizophrenia. Schizophr Res 1995; 17: 5-13.

[55] Langdon R, Coltheart M, Ward PB. Empthetic perspective-taking is impaired I schizophrenia: evidence from a study of emotion attribution and theory of mind. Cogn Neuropsychiatry 2006; 11133-55.

[56] Pilowsky T, Yirmiya N, Arbelle S, Mozes T. Theory of mind abilities of children with schizophrenia, children with autism, and normally developing children. Schizophr Res 2000; 42: 145-55.

[57] Krstev H, Jackson H, Maude D. An investigation of attributional style in firstepisode psychosis. Br J Clin Psychol 1999; 38 (Pt 2): 181-94.

[58] Edwards J, Pattison PE, Jackson HJ, Wales RJ. Facial affect and affective prosody recognition in first-episode schizophrenia. Schizophr Res 2001; 48: 235-53.

[59] Addington J, Saeedi H, Addington D. Facial affect recognition: a mediator between cognitive and social functioning in psychosis? Schizophr Res 2006; 85: $142-50$.

[60] Herbener ES, Hill SK, Marvin RW, Sweeney JA. Effects of antipsychotic treatment on emotion perception deficits in first-episode schizophrenia. Am J Psychiatr 2005;162(9):1746-1748.

[61] Pinkham AE, Penn DL, Perkins DO, Graham KA, Siegel M. Emotion perception and social skill over the course of psychosis: A comparison of individuals "at-risk" for psychosis and individuals with early and chronic schizophrenia spectrum illness. Cognit Neuropsychiatry 2007;12(3):198-212

[62] Inoue $\mathrm{Y}$, Yamada K, Hirano M, Shinohara M, Tamaoki T, Iguchi H, Tonooka $\mathrm{Y}$, Kanba S. Impairment of theory of mind in patients in remission following first episode of schizophrenia. Eur Arch Psychiatry Clin Neurosci 2006; 256: 326-28.

[63] Kettle JWL, O'Brien-Simpson L, Allen NB . Impaired theory of mind in firstepisode schizophrenia: comparison with community, uinverity and depressed controls. Schizophr Res 2008; 99: 96-102.

[64] Kelemen O, Erdélyi R, Pataki I, Benedek G, Janka Z, Kéri S. Theory of mind and motion perception in schizophrenia. Neuropsychology 2005; 19: 494-500.

[65] Sproung M, Schothorst P, Vos E, Hoz J, van Engeland H. Theory of mind in schizophrenia: meta-analysis. Br J Psychiatry 2007; 191: 5-13.

[66] Bertrand MC, Sutton H, Achim AM, Malla AK, Lepage M. Social cognitive impairments in first episode psychosis. Schizophr Res 2007; 95(1-3): 124-33.

[67] Achim AM, Ouellet R, Roy MA, Jackson PL. Mentalizing in first-episode 
psychosis. Psychiatry Res 2012; 196(2-3): 207-13.

[68] Thompson A, Papas A, Bartholomeusz C, Allott K, Amminger GP, Nelson B, Wood S, Yung A. Social cognition in clinical "at risk" for psychosis and first episode psychosis populations. Schizophr Res 2012; 141: 204-9.

[69] Vohs JL, Lysaker PH, Francis MM, Hamm J, Buck KD, Olesek K, Outcalt J, Dimaggio G, Leonhardt B, Liffick E, Mehdiyoun N, Breier A. Metacognition, social cognition, and symptoms in patients with first episode and prolonged psychoses. Schizophr Res 2014; 153(1-3): 54-9.

[70] Langdon R, Connors MH, Still M, Ward PB, Catts S. Theory of mind and neurocognition in early psychosis: a quasi-experimental study. BMC Psychiatry 2014; 14: 316. doi: 10.1186/s12888-014-0316-6.

[71] Bora E, Pantelis C: Theory of mind impairments in first-episode psychosis, individuals at ultra-high risk for psychosis and in first-degree relatives of schizophrenia: systematic review and meta-analysis. Schizophr Res 2013; 144: 31-36.

[72] Ho KK, Lui SS, Hung KS, Wang Y, Li Z, Cheung EF, Chan RC. Theory of mind impairments in patients with first-episode schizophrenia and their unaffected siblings. Schizophr Res. 2015; 166: 1-8.

[73] Mazza, M., Di Michele, V., Pollice, R., Casacchia, M., Roncone, R., 2008. Pragmatic language and theory of mind deficits in people with schizophrenia and their relatives. Psychopathology 41 (4), 254-63.

[74] Mo S, Su Y, Chan RC, Liu J. Comprehension of metaphor and irony in schizophrenia during remission: the role of theory of mind and IQ. Psychiatry Res 2008; 157: 21-29.

[75] Keshavan M, Montrose DM, Rajarethinam R, Diwadkar V, Prasad K, Sweeney JA. [2008]. Psychopathology among offspring of parents with schizophrenia: relationship to premorbid impairments. Schizophr Res 2008; 103: 114-120.

[76] Giuliano AJ, Li H, Mesholam-Gately RI, Sorenson SM, Woodberry KA, Seidman LJ. Neurocognition in the psychosis risk syndrome: a quantitative and qualitative review. Curr Pharm Des 2012; 18: 399-415.

[77] Fusar-Poli P, Bonoldi I, Yung AR, Borgwardt S, Kempton MJ, Valmaggia L, Barale F, Caverzasi E, McGuire P. Predicting psychosis: meta- analysis of transition outcomes in individuals at high clinical risk. Arch. Gen. Psychiatry 2012; 69: 220-22.

[78] Thompson AD, Bartholomeusz C, Yung AR. Social cognition deficits and the 'ultra high risk' for psychosis population: a review of literature. Early Interv Psychiatry 2011; 5: 192-202.

[79] Stanford AD, Messinger J, Malaspina D, Corcoran CM. Theory of mind inpatients at clinical high risk for psychosis. Schizophr Res 2011; 131: 11-17.

[80] Sitskoorn MM, Aleman A, Ebisch SJ, Appels MC, Kahn RS. Cognitive deficits in relatives of patients with schizophrenia: a meta-analysis. Schizophr Res 2004; 71: 285-95.

[81] Snitz BE, Macdonald AW 3rd, Carter CS. Cognitive deficits in unaffected firstdegree relatives of schizophrenia patients: a meta-analytic review of putative endophenotypes. Schizophr Bull 2006; 32:179-94.

[82] Versmissen D, Janssen I, Myin-Germeys I, Mengelers R, Campo J, van Os J, Krabbendam L. Evidence for a relationship between mentalising deficits and paranoid over the psychosis continuum. Schizophr Res 2008; 99: 103-10.

[83] Anselmetti S, Bechi M, Bosia M, Quarticelli C, Ermoli E, Smeraldi E, Cavallaro 
R. 'Theory' of mind impairments in patients affected by schizophrenia and in their parents. Schizophr Res 2009; 115: 278-85.

[84] Janssen I, Krabbendam L, Jolles J, van Os J. Alterations in theory of mind in patients with schizophrenia and non-psychotic relatives. Acta Psychiatr Scan 2003; 108: 110-17.

[85] Yucel MO, Devrimci-Ozguveb H, Ozel ET, Haran S, Saka MC, Atbasoglu EC. Theory of mind deficits in unaffected relatives of patients with schizophrenia and bipolar disorder. Eur Neuropharmacol 2009; 19 (Suppl. 3): 5322.

[86] Riveros R, Manes F, Hurtado E, Escobar M, Martin Reyes M, Cetkovich M, I bañez A. Context-sensitive social cognition is impaired in schizophrenic patients and their healthy relatives. Schizophr Res 2010; 116: 297-98.

[87] Montag C, Neuhaus K, Lehmann A, Krüger K, Dziobek I, Heekeren HR, Heinz A, Gallinat J. Subtle deficits of cognitive theory of mind in unaffected firstdegree relatives of schizophrenia patients. Eur Arch Psychiatry Clin Neurosci. 2012; 262: 217-26.

[88] Marjoram D, Job DE, Whalley HC, Gountouna VE, Mclntosh AM, Simonotto $E$, Cunningham-Owens D, Johnstone EC, Lawrie S. A visual joke fMRI investigation into Theory of Mind and enhanced risk of schizophrenia. Neurolmage 2006; 31(4): 1850-58.

[89] de Achával D, Costanzo EY, Villarreal M, Jáuregui IO, Chiodi $A$, Castro MN, Fahrer RD, Leiguarda RC, Chu EM, Guinjoan SM. Emotion processing and theory of mind in schizophrenia patients and their unaffected first-degree relatives. Neuropsychologia 2010; 48: 1209-15.

[90] Kelemen O, Erdélyi R, Pataki I, Benedek G, Janka Z, Kéri S. Theory of mind and motion perception in schizophrenia. Neuropsychology. 2005; 19(4):494-500.

[91] Marjoram D, Miller P, Mclntosh AM, Cunningham Owens DG, Johnstone EC, Lawrie S. A neuropsychological investigation into 'Theory of mind' and enhanced risk of schizophrenia. Psychiatry Res 2006; 144: 29-37.

[92] Pentaraki AD, Stefanis NC, Stahl D, Theleritis C, Toulopoulou T, Roukas D, Kaliora SC, Chatzimanolis I, Smyrnis N, Russell T, Kravariti E, Murray RM. Theory of Mind as a potential trait marker of schizophrenia: a family study. Cogn Neuropsychiatry 2012; 17: 64-89.

[93] Heinrichs RW, Zakzanis KK. Neurocognitive deficit in schizophrenia: a quantitative review of the evidence. Neuropsychology 1998; 12: 426-45.

[94] Koelkebeck K, Pedersen A, Suslow T, Kueppers KA, Arolt V, Ohrmann P. Theory of Mind in first-episode schizophrenia patients: correlations with cognition and personality traits. Schizophr Res. 2010; 119(1-3):115-23.

[95] Bliksted V, Fagerlund B, Weed E, Frith C, Videbech P. Social cognition and neurocognitive deficits in first-episode schizophrenia. Schizophr Res 2014; 153: 9-17.

[96] Ozonoff S, Pennington BF, Rogers SJ. Executive function deficits in highfunctioning autistic individuals: relationship to theory of mind. J Child Psychol Psychiatry 1991; 32:1081-105.

[97] Frye D, Zelazo PD, Brooks PJ, Samuels MC. Inference and action in early causal reasoning. Dev Psychol 1996; 32: 120-31.

[98] Hughes C. Executive function in preschoolers: links with theory of mind and verbal ability. Br J Dev Psychol 1998a; 16: 233-53.

[99] Perner J, Lang B. Theory of mind and executive function: is there a developmental relationship? In: Baron-Cohen S, Tager-Flusberg $\mathrm{H}$, Cohen 
DJ, editors. Understanding other minds: perspectives from developmental cognitive neuroscience. 2nd ed. Oxford: Oxford University Press; 2000. p. $150-81$.

[100] Vyas NS, Shamsi SA, Malhotra AK, Aitchison KJ, Kumari V. Can genetics inform the management of cognitive deficits in schizophrenia? J Psychopharmacol 2012; 26: 334-48.

[101] Vyas NS, Patel NH, Herscovitch P, Puri BK, Lanzenberger R. Recent developments in neurochemical imaging in schizophrenia: an update. Curr Med Chem. 2013; 20: 351-6.

[102] Díaz-Mataix L, Scorza MC, Bortolozzi A, Toth M, Celada P, Artigas F. Involvement of 5-HT1A receptors in prefrontal cortex in the modulation of dopaminergic activity: role in atypical antipsychotic action. J Neurosci. 2005; 25:10831-43.

[103] Bosia M, Lorenzi C, Pirovano A, Guglielmino C, Cocchi F, Spangaro M, Bramanti P, Smeraldi E, Cavallaro R. COMT Val158Met_and 5-HT1A-R $1019 \mathrm{C} / \mathrm{G}$ polymorphisms: effects on the negative symptom response to clozapine. Pharmacogenomics 2015; 16: 35-44.

[104] Vyas NS, Patel NH, Nijran KS, Al-Nahhas A, Puri BK. Can_PET/CT imaging advance our understanding of the neurobiology of schizophrenia? Nucl Med Commun. 2010; 31: 91-3.

[105] Patel NH, Vyas NS, Puri BK, Nijran KS, Al-Nahhas A. Positron emission tomography in_schizophrenia: a new perspective. J Nucl Med 2010; 51: 51120.

[106] Howes OD, Kapur S. The dopamine hypothesis of schizophrenia: version III-the final common pathway. Schizophr Bull. 2009; 35: 549-62.

[107] Alfimova MV, Golimbet VE, Korovaitseva GI, Aksenova EV, Lezheiko TV, Abramova LI, Yu N. Kolesina, I. M. Anua, T. M. Savel'eva (2015). Association of the COMT and DRD2 genes with the ability of schizophrenia patients to understand the mental state of other people. Neuroscience and Behavioural Physiology, 45, 1, 12-18.

[108] O'Donovan MC, Craddock N, Norton N, Williams H, Peirce T, Moskvina V et al Identification of loci associated with schizophrenia by genome-wide association and follow-up. Nat Gen 2008; 40: 1053-1055.

[109] Donohoe G, Morris DW, Corvin A. The psychosis susceptibility gene ZNf804a: associations, functions, and phenotypes. Schizophr Bull 2010; 36: 904-909.

[110] Steinberg S, Mors O, Børglum AD, Gustafsson O, Werge T, Mortensen PB et al Expanding the range of ZNF804A variants conferring risk of psychosis.Mol Psychiatry 2011; 16: 59-66.

[111] Hargreaves A, Morris DW, Rose E, Fahey C, Moore S, Cummings E, Tropea D, Gill M, Corvin A, Donohoe G. ZNF804A and social cognition in patients with schizophrenia and healthy controls. Mol Psychiatry. 2012; 17:118-9.

[112] Walters JT, Corvin A, Owen MJ, Williams H, Dragovic M, Quinn EM et al Psychosis susceptibility gene ZNF804A and cognitive performance in schizophrenia. Arch Gen Psychiatry. 2010; 67: 692-700.

[113] Amodio DM, Frith CD. Meeting of minds: the medial frontal cortex and social cognition. Nature reviews. Neuroscience 2006; 7(4): 268-277.

[114] Blakemore SJ. The social brain in adolescence. Nature reviews.

Neuroscience 2008; 9(4): 267-77. 
[115] Frith U, Frith CD. Development and neurophysiology of mentalizing. Philosophical Transactions of the Royal Society B: Biological Sciences 2003; 358(1431): 459-473.

[116] Brunet, E., Sarfati, Y., Hardy-Bayle, M.C., Decety, J., 2000. A PET investigation of the attribution of intentions with a nonverbal task. Neurolmage 11(2): 157-166.

[117] Vollm BA, Taylor AN, Richardson P, Corcoran R, Stirling J, McKie S et al. Neuronal correlates of theory of mind and empathy: a functional magnetic resonance imaging study in a nonverbal task. Neurolmage 2006; 29: 90-98.

[118] Schurz M, Radua J, Aichhorn M, Richlan F, Perner J. Fractionating theory of mind: A meta-analysis of functional brain imaging studies. Neuroscience \& Biobehavioral Reviews 2014; 42: 9-34.

[119] Hooker Cl, Bruce L, Lincoln SH, Fisher M, Vinogradov S. Theory of mind skills are related to gray matter volume in the ventromedial prefrontal cortex in schizophrenia. Biol Psychiatry 2011; 70: 1169-1178.

[120] Benedetti F, Bernasconi A, Bosia M, Cavallaro R, Dallaspezia S, Falini A, et al. Functional and structural brain correlates of theory of mind and empathy deficits in schizophrenia. Schizophrenia research 2009; 114(1-3): 154-60.

[121] Koelkebeck K, Hirao K, Miyata J, Kawada R, Saze T, Dannlowski U, et al. Impact of gray matter reductions on theory of mind abilities in patients with schizophrenia. Soc Neurosci 2013; 8(6): 631-639.

[122] Brunet-Gouet E, Decety J. Social brain dysfunctions in schizophrenia: a review of neuroimaging studies. Psychiatry Res 2006; 148: 75-92.

[123] Dodell-Feder D, Tully LM, Lincoln SH, Hooker Cl. The neural basis of theory of mind and its relationship to social functioning and social anhedonia in individuals with schizophrenia. Neurolmage. Clinical 2014; 4: 154-63.

[124] Lee KH, Brown WH, Egleston, PN, Green RD, Farrow TF, Hunter MD, Parks RW, Wilkinson ID, Spence SA, Woodruff, PW. A functional magnetic resonance imaging study of social cognition in schizophrenia during an acute episode and after recovery. Am J Psychiatry 2006; 163: 1926-33.

[125] Brune, M., Ozgurdal, S., Ansorge, N., von Reventlow, H.G., Peters, S., Nicolas, $V$ et al. An fMRI study of "theory of mind" in at-risk states of psychosis: comparison with manifest schizophrenia and healthy controls. Neurolmage 2011; 55(1): 329-337.

[126] Modinos G, Renken R, Shamay-Tsoory SG, Ormel J, Aleman A. Neurobiological correlates of theory of mind in psychosis proneness. Neuropsychologia 2010; 48(13):3715-24.

[127] Shamay-Tsoory SG, Tibi-Elhanany Y, Aharon-Peretz, J. The ventromedial prefrontal cortex is involved in understanding affective but not cognitive theory of mind stories. Social Neuroscience 2006; 1(3-4): 149-166.

[128] Chapman LJ, Chapman JP, Raulin ML. Scales for physical and social anhedonia. J Abnorm Psychol1976; 85(4): 374-82.

[129] Wang Y, Liu WH, Li Z, Wei XH, Jiang XQ, Neumann DL, Shum DH, Cheung EF, Chan RC. Dimensional schizotypy and social cognition: An fMRI imaging study. Front Behav Neurosci 2015; 9: 133.

[130] Dodell-Feder, D., DeLisi, L.E., Hooker, C.I., 2014a. Neural disruption to theory of mind predicts daily social functioning in individuals at familial high-risk for 
schizophrenia. Social cognitive and affective neuroscience 9(12), 1914-1925.

[131] van der Meer L, Groenewold NA, Pijnenborg M, Aleman A. Psychosis-

Proneness and Neural Correlates of Self-Inhibition in Theory of Mind.

PloS one 2013; 8(7): e67774.

[132] Brune M. Emotion recognition, "theory of mind", and social behaviour in schizophrenia. Psychiatry Res 2005; 133: 135-47.

[133] Sprong M, Schothorst P, Vos E, Hox J, Van Engeland H. Theory of mind in schizophrenia meta-analysis. Br J Psychiatry 2007; 191: 5-13. 